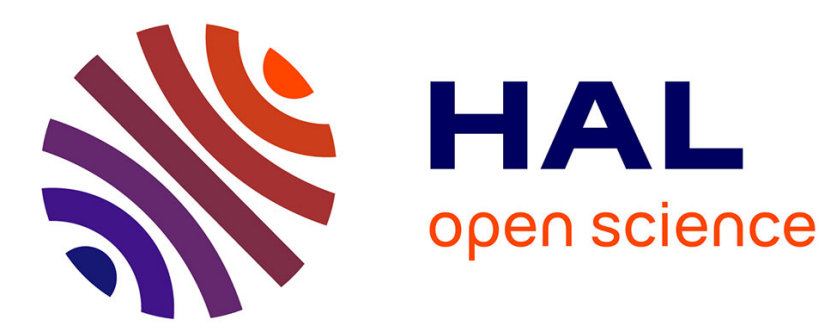

\title{
Analysis of Oil Recovery by Spontaneous Imbibition of Surfactant Solution
}

T. Babadagli

\section{To cite this version:}

T. Babadagli. Analysis of Oil Recovery by Spontaneous Imbibition of Surfactant Solution. Oil

\& Gas Science and Technology - Revue d'IFP Energies nouvelles, 2005, 60 (4), pp.697-710. 10.2516/ogst:2005049 . hal-02017225

\section{HAL Id: hal-02017225 \\ https://hal.science/hal-02017225}

Submitted on 13 Feb 2019

HAL is a multi-disciplinary open access archive for the deposit and dissemination of scientific research documents, whether they are published or not. The documents may come from teaching and research institutions in France or abroad, or from public or private research centers.
L'archive ouverte pluridisciplinaire HAL, est destinée au dépôt et à la diffusion de documents scientifiques de niveau recherche, publiés ou non, émanant des établissements d'enseignement et de recherche français ou étrangers, des laboratoires publics ou privés. 


\title{
Analysis of Oil Recovery by Spontaneous Imbibition of Surfactant Solution
}

\author{
T. Babadagli ${ }^{1}$ \\ 1 University of Alberta, Department of Civil and Environmental Eng., School of Mining and Petroleum, \\ 3-1 12 Markin CNRL/NREF Bldg., Edmonton, AB, T6G 2W2 - Canada \\ e-mail:tayfun@ualberta.ca
}

\begin{abstract}
Résumé - Analyse de la récupération d'huile par imbibition spontanée d'une solution de surfactant - Selon le type de roche et d'huile, une réduction de la tension interfaciale (IFT) par l'addition d'un agent tensio-actif à la saumure peut augmenter la récupération capillaire avec l'appui du drainage dans les réservoirs naturellement fracturés (NFR). Cet article vise à identifier et analyser les mécanismes de récupération et à calculer les effets de mise à l'échelle pour la récupération d'huile de différents types de roche par l'imbibition (spontanée) capillaire d'une solution d'agent tensio-actif.
\end{abstract}

Des essais en laboratoire ont été exécutés en utilisant quatre types de roche représentatives des matrices de réservoir d'une NFR (grès, calcaire, calcaire dolomitique et craie). L'échantillon de grès était couvert en surface pour créer une barrière, imposant l'interaction uniquement à contre-courant. Une grande variété d'huiles (bruts légers et lourds, kérosène, et huile à moteur) a été choisie comme phase oléique. Différents types (non ioniques et anioniques) et concentrations des agents tensio-actifs ont été employés comme phase aqueuse avec une saumure comme situation de référence. Les échantillons entièrement saturés d'huile $\left(S_{\mathrm{wi}}=0\right)$ ont été exposés à l'imbibition capillaire statique et la récupération suivie en fonction du temps. Quelques expériences sur les craies ont été répétées en utilisant les échantillons présaturés $\left(S_{\mathrm{wi}}>0\right)$ afin de clarifier les changements des caractéristiques capillaires d'imbibition de la roche. Les changements (positifs ou négatifs) du taux de récupération et de la récupération finale, comparés à l'imbibition par la saumure, ont été évalués en fonction des types de roche, d'agent tensio-actif et de pétrole. On a observé, pour certains types de roche, que la récupération par imbibition par la solution d'agent tensioactif est exclusivement contrôlée par la concentration de l'agent tensio-actif. La différence dans le taux de récupération et de la récupération finale entre faible et forte IFT pourraient être dus non seulement au changement de l'IFT mais également au changement de la mouillabilité et de l'absorption, qui pourraient changer avec le type de roche. Ceci a été également analysé en utilisant la forme des courbes qui indique l'effet de la capillarité sur la récupération et le type d'interaction, c'est-à-dire, co- ou contre-courant.

En plus de l'analyse qualitative mentionnée ci-dessus, les courbes de récupération ont été évaluées pour la mise à l'échelle. Des descriptions existantes sans dimension ont été examinées. L'exercice de mise à l'échelle aide à identifier si la récupération est dirigée par des forces de pesanteur ou de capillarité et pour clarifier le type d'interaction, co- ou contre-courant ou les deux. Les récupérations finales ont été corrélées avec le nombre inverse de Bond, en utilisant vingt-cinq cas couvrant différentes combinaisons de quatre types de roche, quatre huiles et quatre types d'agent tensio-actif.

Abstract - Analysis of Oil Recovery by Spontaneous Imbibition of Surfactant Solution - Depending on rock and oil type, lowered interfacial tension (IFT) by the addition of surfactant to brine may contribute to capillary imbibition recovery with the support of gravity drainage in naturally fractured 
reservoirs (NFR). This paper aims at identifying and analyzing the recovery mechanisms and performing up-scaling exercises for oil recovery from different rock types by the capillary (spontaneous) imbibition of surfactant solution.

Laboratory tests were performed using four different rock types that could possibly be the reservoir rock matrix of the NFRs (sandstone, limestone, dolomitic limestone and chalk). The sandstone sample was surface-coated to create a boundary condition causing only counter-current interaction. Wide variety of oils (light and heavy-crude oils, kerosene, and engine oil) was selected as the oleic phase. Different types (non-ionic and anionic) and concentrations of surfactants were used as the aqueous phase as well as the brine as a base case. The samples fully saturated with oil $\left(S_{w i}=0\right)$ were exposed to static capillary imbibition and the recovery was monitored against time. Some experiments on the chalks were repeated using pre-wet samples $\left(S_{w i}>0\right)$ to clarify the changes in the capillary imbibition characteristics of the rock.

The changes (positive or negative) in the recovery rate and ultimate recovery compared to the brine imbibition were evaluated for the rock, surfactant and oil types. It was observed, for some rock samples, that the imbibition recovery by surfactant solution was strictly controlled by the concentration of the surfactant. The difference in the recovery rate and ultimate recovery between high and low IFT could be due not only to change in the IFT but also the change in the wettability and adsorption, which might vary with the rock type. This was also analyzed using the shape of the curves that indicates the strength of the capillarity on the recovery and the interaction type, i.e., co- or counter-current.

In addition to the above-mentioned qualitative analysis, the recovery curves were evaluated for upscaling. Existing dimensionless scaling groups were tested. The scaling exercise helped identify whether the recovery is driven by gravity or capillary forces and clarify the interaction type, i.e., co-or countercurrent or both. The ultimate recoveries were correlated to the Inverse Bond Number using twenty-five cases covering different combinations of four rock types, four oil and four surfactant samples.

\section{NOTATIONS}

$A_{i} \quad$ area open to imbibition at the ith direction $\left(\mathrm{cm}^{2}\right)$

c constant

C constant

CMC critical micelle concentration

EOR enhanced oil recovery

$f(\theta) \quad$ certain function of wettability/capillarity

$F_{\text {s }} \quad$ matrix shape factor

$H \quad$ matrix height $(\mathrm{cm})$

IFT interfacial tension, dyne $/ \mathrm{cm}(\mathrm{mN} / \mathrm{m})$

$k \quad$ matrix permeability $(\mathrm{mD})$

$l_{A i} \quad$ distance from Ai to no-flow boundary $(\mathrm{cm})$

$L \quad$ matrix size $(\mathrm{cm})$

Lc modified characteristic length $(\mathrm{cm})$

$n$ total number of surfaces open to imbibition

$R \quad$ matrix radius $(\mathrm{cm})$

$t \quad$ time (min)

$t_{d} \quad$ dimensionless time for capillary imbibition recovery

$t_{g} \quad$ dimensionless time for imbibition recovery governed by gravity forces

$V_{b} \quad$ bulk volume of matrix (cc)

$\phi \quad$ porosity

$\lambda$ mobility

$\mu_{g m} \quad$ geometric mean of oil and water viscosities (cp)

$\mu_{o} \quad$ oil viscosity (cp)

$\mu_{w} \quad$ water viscosity (cp)

$\rho \quad$ density $(\mathrm{g} / \mathrm{cc})$

$\sigma \quad$ interfacial tension, dyne $/ \mathrm{cm}(\mathrm{mN} / \mathrm{m})$.

\section{INTRODUCTION}

Injection of surfactant solution into naturally fractured reservoirs (NFR) has gained a great deal of attention in recent years. Although reported field cases are limited, considerable amount of laboratory studies have appeared in literature. Capillary imbibition recovery can be enhanced by the addition of surfactant into water to reduce the IFT. Depending on the size and wettability characteristics of the reservoir matrix, the gravitational forces might play a role in the matrix recovery as well.

Different aspects of capillary imbibition of low IFT aqueous phase were studied in the past [1-13]. The changes on the rock-fluid and fluid-fluid interactions due to surfactant addition could act in different ways in oil recovery by capillary imbibition. It has been observed that the reduction in IFT yields higher ultimate recovery but slower imbibition rate [3$6,10]$ for water wet sandstone samples. Babadagli $[13,14]$ reported that the capillary imbibition of low IFT solution (with a non-ionic surfactant) was faster than high IFT case when a light crude oil is used with a limestone sample. Austad et al. [9] observed the same for chalks with cationic surfactant. Keijzer and deVries [1] showed that the surfactant imbibition did not yield any incremental recovery for water-wet sandstone but some effects were observed on the recovery rate.

In case of unfavorable matrix boundary conditions, that do not allow interaction from all sides of matrix, surfactant solution may yield lower ultimate recovery and lower recovery rate than those of brine $[10,15]$. In addition to the 
physical boundary condition, the interaction could be controlled by the strength of the capillary forces that eventually yields co-or counter-current (or both) interaction. This might eventually affect the ultimate recovery and recovery rate $[4,7]$. As the capillary forces become stronger, i.e., strongly water wet rocks or higher IFT, the capillary imbibition dominates the recovery. One can expect fully counter-current type interaction for this case. As the capillary forces weaken, i.e., larger matrix block sizes or less water wet rock or lowered IFT, the effect of the gravity on the interaction between matrix and fracture could be felt. That might cause a fully co-current matrix-fracture transfer.

Wettability alteration by surfactant addition into brine can be expected depending on the rock and surfactant type [16, 17]. Incompatibility of the rock with surfactant type might give rise to adsorption $[7,8]$. They both play a role on the recovery rate and ultimate recovery. Surfactant degradation due to factors other than temperature is another possibility as well. Thus, the performance of the surfactant solution as an imbibition fluid could be controlled by the rock properties (wettability, lithology, matrix boundary condition and adsorption) and the characteristics of surfactant. Therefore, the selection of the proper surfactant type and amount for different rock and oil types is the key factor. Due to complexities caused by so many parameters involved in the process, no procedure has so far been suggested in terms of the selection of the surfactant type and the application of the technique for effective capillary imbibition recovery in NFR.

One of the key factors that affects the rock-oil-surfactant solution interaction towards the oil recovery is the existence (an the amount) of initial water. Although the effects of initial water on the imbibition of high IFT cases were studies to some extent [18-20], studies on low IFT imbibition is limited. This is expected to affect the wettability and adsorption characteristics of the rock as well.

The objective of this paper is to present an extensive analysis of the capillary (spontaneous) imbibition of surfactant solutions into oil saturated rocks. Three characteristic rock types that are commonly encountered in NFRs and wide variety of oil types were tested for different surfactant types. The results were evaluated in terms of oil recovery rate and ultimate recovery. Different scaling groups were also applied to clarify the scaling behavior explicitly and the mechanics of the recovery implicitly.

\section{EXPERIMENTAL STUDY}

Six different types of oil (3 synthetic or processed, other three crude oil) and four different types of surfactants (solutions) were selected as the oleic and aqueous phases. The details about the fluid properties are given in Table 1 . IFTs were measured using the ring method. The error estimated in the IFT measurements is estimated around
7-9\%. The measurements were performed several times for each surfactant concentration and the arithmetic mean of the values obtained were used as the final IFT value for a given surfactant concentration. The critical micelle concentration (CMC) values for each surfactant solution used in the experimentation are given in Table 1 .

Experiments were conducted on four different rock samples (Table 1). Sandstone and one type of limestone (LS-1) samples are outcrops. Plugs were taken from the same block to ensure that the rock properties are identical. The other type limestone (LS-2) and chalk samples are from oil producing formations. The plugs to be used in the experiments were taken out from the same parts of the cores. Those samples were exposed to the same cleaning process using a Soxhlet device. Each sample was used for only one experiment. For counter-current experiments, 1.5 in-diameter sandstone samples were cut halfway vertically and coated using epoxy from all sides except the flat vertical surface. The samples were dried one day in an oven $\left(\right.$ at $\left.80^{\circ} \mathrm{C}\right)$ and fully saturated with oil under vacuum for 24 hours at room temperature. For the samples with initial water, the same procedure was repeated with brine. Then the samples were placed into a Hassler core holder and the brine was displaced by oil until no brine is recovered.

After coating and saturating the samples, they were immersed into an imbibition cell filled with the aqueous phase (brine or surfactant solution) in vertical position and exposed to capillary imbibition at room temperature. The recovery was monitored against time through graduated cylinder allowing volume measurements with a precision of $\pm 0.1 \mathrm{cc}$. A schematic representation of the experimental apparatus is shown in Table 1.

\section{ANALYSIS OF THE RESULTS}

The results, namely the recovery curves, were analyzed qualitatively first. Then, the same data were evaluated against dimensionless numbers. This allowed understanding the scaling behavior as well as the mechanics of the recovery implicitly.

\subsection{Qualitative Analysis}

The recovery curves for all cases are shown in Figures 1 to 4 . The evaluations were made for each rock sample.

\subsubsection{Sandstone}

Lower IFT resulted in an incremental recovery for all oil samples (Fig. 1). In accordance with the previous experience [3-6] where different sandstones were used as rock samples, brine (high IFT) initially shows a faster recovery than that of low IFT. This is true for all cases except the heavy crude oil (Crude Oil-1). The recovery rate turned out to be 
TABLE 1

Rock and fluid properties used in the experiments

\begin{tabular}{|c|c|c|c|c|c|}
\hline Rock Types & Characteristics & $\begin{array}{c}\mathbf{k} \\
(\mathbf{m d})\end{array}$ & $\begin{array}{c}\phi \\
(\%)\end{array}$ & $\begin{array}{c}\text { Length } \\
\text { (cm) }\end{array}$ & $\begin{array}{c}\text { Diameter } \\
\text { (cm) }\end{array}$ \\
\hline Sandstone (SS) & (Unfired Berea Sandstone, Outcrop) & 400 & 20 & $10 \& 7.5$ & $3.8 \& 2.5$ \\
\hline Limestone-1 (LS-1) & (Indiana Limestone, Outcrop) & 17 & 19 & 5 & 2.5 \\
\hline Limestone-2 (LS-2) & (Dolomitic limestone, cleaned core from a producing formation) & 7 & 16 & 7.5 & 2.5 \\
\hline Chalk (CH) & (Cleaned core from a producing formation) & 10 & 28 & 7.5 & 2.5 \\
\hline
\end{tabular}

\begin{tabular}{l|c|c|c|c}
\hline \multicolumn{1}{|c|}{ Aqueous Phases } & Type & $\begin{array}{c}\text { Properties } \\
\text { (major chemical structure })\end{array}$ & $\begin{array}{c}\text { CMC } \\
(\mathbf{C o n c})\end{array}$ & $\begin{array}{c}\text { IFT @ CMC } \\
(\mathbf{d y n e} / \mathbf{c m})\end{array}$ \\
\hline Brine & $3 \% \mathrm{NaCl}$ & - & - \\
\hline Surfactant Solution- 1 (Surf. 1) & $\begin{array}{c}\text { Non-ionic } \\
\text { (SIGMA) }\end{array}$ & $\begin{array}{c}\text { Surfactant (TRITON X-100) } \\
\text { (t-octylphenoxypolyethoxyethanol) }\end{array}$ & $0.4 \%$ \\
\hline Surfactant Solution- 2 (Surf. 2) & Non-ionic & $\begin{array}{c}\text { Surfactant (IGEPAL) } \\
\text { (t-octylphenoxypolyethoxyethanol) }\end{array}$ & - \\
\hline Surfactant Solution- 3 (Surf. 3) & Anionic & $\begin{array}{c}\text { Surfactant/Non-emulsifier } \\
\text { (Diol) }\end{array}$ & $0.5 \%$ & $0.1 \%$ \\
\hline Surfactant Solution- 4 (Surf. 4) & Non-ionic & $\begin{array}{c}\text { Solvent/Surfactant } \\
\text { (ethoxylated nonylphenol) }\end{array}$ & - \\
\hline
\end{tabular}

\begin{tabular}{l|c|c}
\hline Oil Phase & $\begin{array}{c}\mu \\
(\mathbf{c p})\end{array}$ & $\begin{array}{c}\rho \\
(\mathbf{g} / \mathbf{c c})\end{array}$ \\
\hline Kerosene (commercial) & 2 & 0.79 \\
\hline Mineral Oil (commercial) & 175 & 0.88 \\
\hline Engine Oil (commercial) & 640 & 0.89 \\
\hline Crude Oil - 1 (CO-1) & 2200 & 0.95 \\
\hline Crude Oil - 2(CO-2) & 6 & 0.81 \\
\hline Crude Oil - 3 (CO-3) & 19 & 0.83 \\
\hline
\end{tabular}

\begin{tabular}{|c|c|c|c|}
\hline Oil-Aqueous Phase & $\begin{array}{c}\text { CMC } \\
\text { (Conc.) }\end{array}$ & $\begin{array}{l}\text { Surfactant concentration and corresponding IFT } \\
\text { for the fluid pairs given in Figures } 1,2,3 \text {, and } 4\end{array}$ & \multirow{9}{*}{ Experimental Set-up } \\
\hline Kerosene - Surf. 1 & $0.7 \%$ & Above CMC (1\%, 12 dyne/cm) & \\
\hline Mineral Oil-Surf. 2 & $2 \%$ & $\begin{array}{c}\text { Below CMC (1\%, } 7 \text { dyne/cm) } \\
\text { Below CMC (1.5\%, } 4.5 \text { dyne/cm) }\end{array}$ & \\
\hline Engine Oil-Surf. 1 & $0.8 \%$ & Above CMC (1\%, 15 dyne/cm) & \\
\hline CO-1 - Surf. 1 & $2.5 \%$ & Below CMC $(1 \%, 30$ dyne/cm $)$ & \\
\hline CO-2 - Surf. 1 & $2.2 \%$ & Below CMC $(1 \%, 11$ dyne/cm) & \\
\hline CO-3 - Surf. 1 & $0.5 \%$ & Below CMC $(0.1 \%, 1.5$ dyne/cm) & \\
\hline CO-3 - Surf. 3 & $0.05 \%$ & $\begin{array}{c}\text { Below CMC }(0.01 \%, 7 \text { dyne } / \mathrm{cm}) \\
\text { Above CMC }(0.1 \%, 1 \text { dyne/cm })\end{array}$ & \\
\hline Crude Oil 3 - Surf. 4 & $1.2 \%$ & $\begin{array}{l}\text { Below CMC }(0.1 \%, 5 \text { dyne/cm }) \\
\text { Below CMC }(1 \%, 2.5 \text { dyne/cm })\end{array}$ & \\
\hline
\end{tabular}



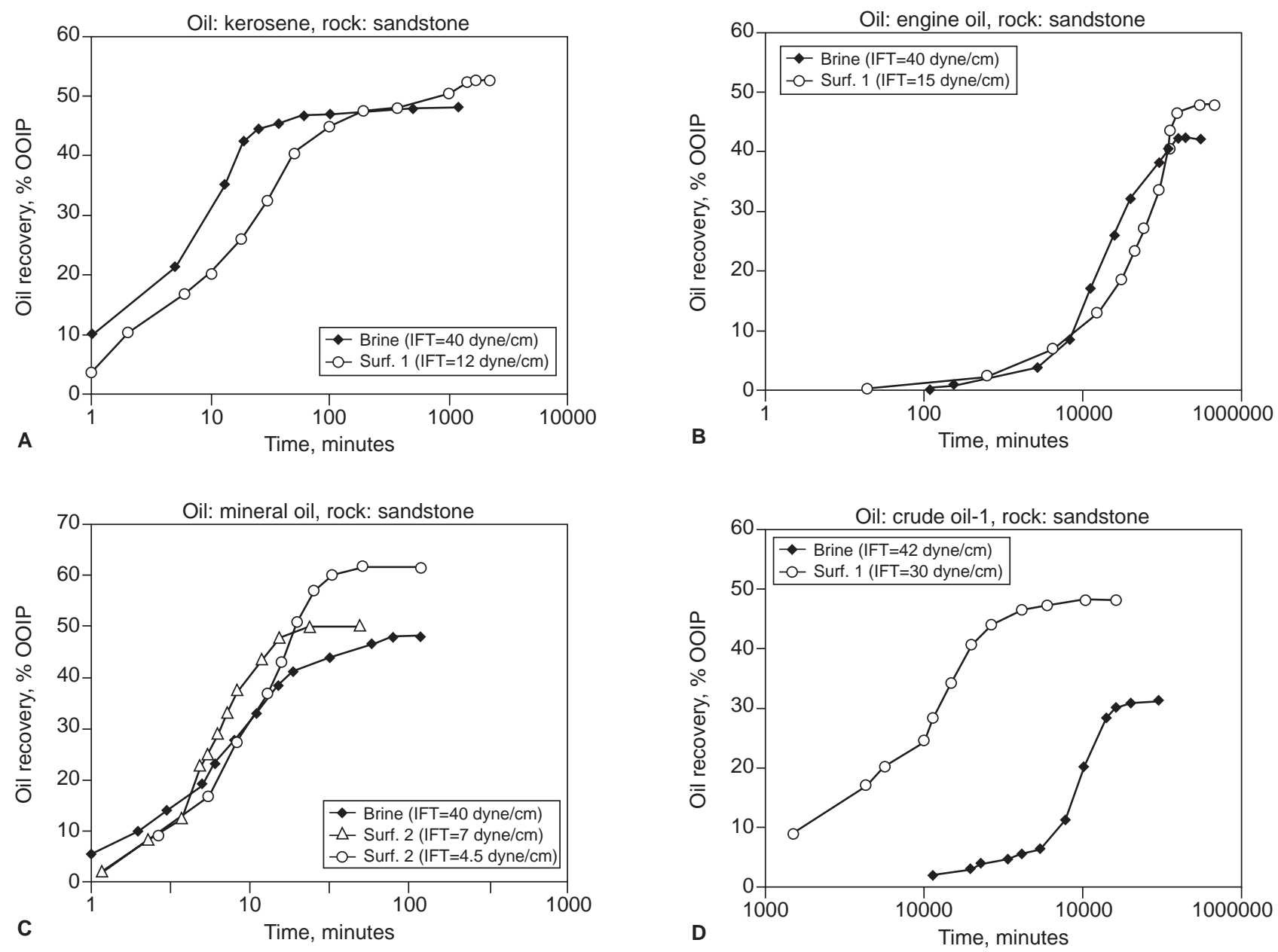

Figure 1

Spontaneous imbibition from cylindrical Berea sandstone for different oleic/aqueous phase pairs.

substantially higher for the surfactant case as well as the ultimate recovery (Fig. 1d). Classical Mattax and Kyte [21] dimensionless group suggests that the recovery rate becomes higher as the IFT increases:

$$
t_{d}=t \frac{\sigma}{\mu_{w} L^{2}} \sqrt{\frac{k}{\phi}}
$$

This observation is in disagreement with this equation. The remarkable change in the recovery rate could be attributed to the changes in wettability [16-17]. Previously, Alveskog et al. [16] observed that anionic surfactants change the wettability of sandstones from strongly water-wet to weakly oil-wet. Standnes and Austad [17] reported that the wettability of chalks is changed from oil-wet to water-wet with cationic surfactants. In the experiments given in Figure 1, a non-ionic surfactant was used.
Other three oil cases yielded a faster recovery with brine in early times and the low IFT imbibition turned out to be faster in late times (Figs. 1a, b, and c). One can conclude that the recovery is not dominated by the capillary forces for both high and low IFT cases in Figure 1d when compared to the ones in Figures 1a and c.

As mentioned earlier, the matrix fracture interaction is expected to be in counter-current manner if the rock is strongly water wet, i.e., the capillary forces dominate the imbibition process $[4,7,22]$. The imbibition front progresses uniformly towards to the inner part of the core from all sides based on the observations from the visualization studies [18]. As the capillary forces dwindle, the interaction between matrix and fracture becomes co-current, i.e., water driving oil from bottom part in upward direction. This happens in case of long matrix [4, 7] and oil-wet systems [22]. If, however, all the sides of the matrix are close to flow except the bottom side, the counter-current flow occurs irrespective of the wettability and size of the matrix. Figure 2 represents this 
case for two oil types. Figures 1a and 2a illustrate the same cases except the physical boundary conditions. Both cases
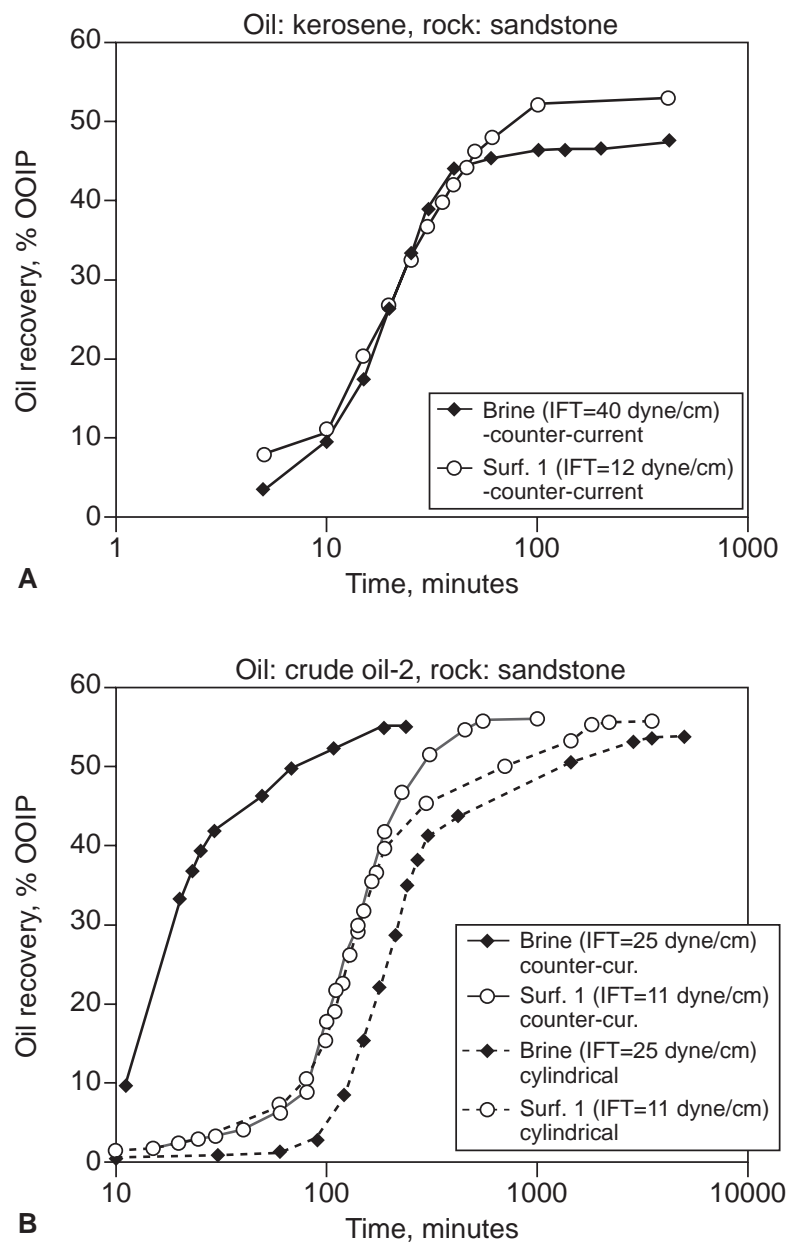

Figure 2

Spontaneous (capillary) imbibition from semi-cylindrical Berea sandstone (counter-current flow) for different oleic/ aqueous phase pairs. For comparison, cylindrical sample (all sides open) was included for crude-oil 2.

are expected to yield a very strong capillary imbibition in counter-current manner due to favorable conditions (strongly water wet, high IFT, low oil viscosity, and high permeability) even though the counter-current interaction for the latter is due to physical boundary conditions. The shape of the curves proves a counter-current imbibition driven by strong capillary forces. The imbibition starts within five minutes followed by a steep straight line until it levels off. Low IFT yields higher ultimate recovery for both cases as well.

Figure $2 \mathrm{~b}$ shows the comparison of fully open cylindrical and semi-cylindrical (one side open) cases for crude oil-2. The recovery curves imply that the imbibition in the cylindrical cores with all sides open is not fully dominated by the capillary forces. The same can be said for the low IFT case for counter-current flow (semi-cylindrical sample with one side open to flow). In fact these three cases followed the same recovery trend and eventually, the low IFT case yielded a higher recovery. Note, however, that the high IFT case of counter-current flow is strongly capillary dominated interaction and the recovery trend is identical to the kerosene case shown in Figure 2a. This behavior is in accordance with Equation (1), i.e., the higher the IFT, the faster the recovery. Apparently, totally counter-current type transfer did not occur for crude oil (CO-2) recovery from the cylindrical cores and low and high IFT did not show any remarkable difference in terms of the recovery rate (dotted lines in Figure 2b). As opposed to this case, the recovery rates and trends are different for the high and low IFT cases of the semi-cylindrical sample where the interaction is totally counter-current for the high IFT case.

\subsubsection{Limestone}

The recovery curves for two types of limestone and two types of crude oil are shown in Figure 3. It is clear that the interaction is not capillary dominated since the recoveries are low and the time required for this recovery is very long. The cases shown in Figure $3 \mathrm{~b}$ could be exceptional as the ultimate recoveries are higher than the other limestone cases. The ultimate recoveries indicate that this is a capillary dominated recovery. The difference between Figures $3 \mathrm{a}$ and $\mathrm{b}$ can be attributed to the wettability and adsorption characteristics as the two limestones samples differ from each other by origin. For all the cases, on the other hand, the trend is the same, i.e., lower the IFT, higher the ultimate recovery and faster the recovery.

\subsubsection{Chalk}

The chalk sample exhibited a similar performance as the limestone in terms of the recovery trend, i.e., surfactant yielded faster and higher ultimate recovery. The case shown in Figure 4a suggests that the interaction is not fully dominated by capillarity, as similar to the case shown in Figure $3 \mathrm{a}$. The ultimate recovery is not as high as the case shown in Figure $3 b$ but higher than the cases in Figures 3a and c. The chalk sample followed a similar recovery trend to the limestone samples but not to the sandstone.

More attention was given to chalk case due to existing EOR potential in fractured chalk reservoirs $[2,7-9,11,12$, 16, 17]. Different surfactant types were tested without changing the oil type. Figures $4 \mathrm{~b}$ and $\mathrm{c}$ show the results for two different surfactant types. Some of the tests were repeated with initial water as well. Surf. 3 (an anionic surfactant) showed an IFT dependent imbibition. When IFT was $7 \mathrm{dyne} / \mathrm{cm}$, the recovery rate and the ultimate recovery were lower than those of brine. The opposite was observed for IFT $=1$ dyne/cm case. If the initial water exits (irreducible water saturation is around 20\%), both the brine and surfactant solutions yielded faster recovery and higher ultimate recovery with increasing surfactant concentration (decreasing IFT). 

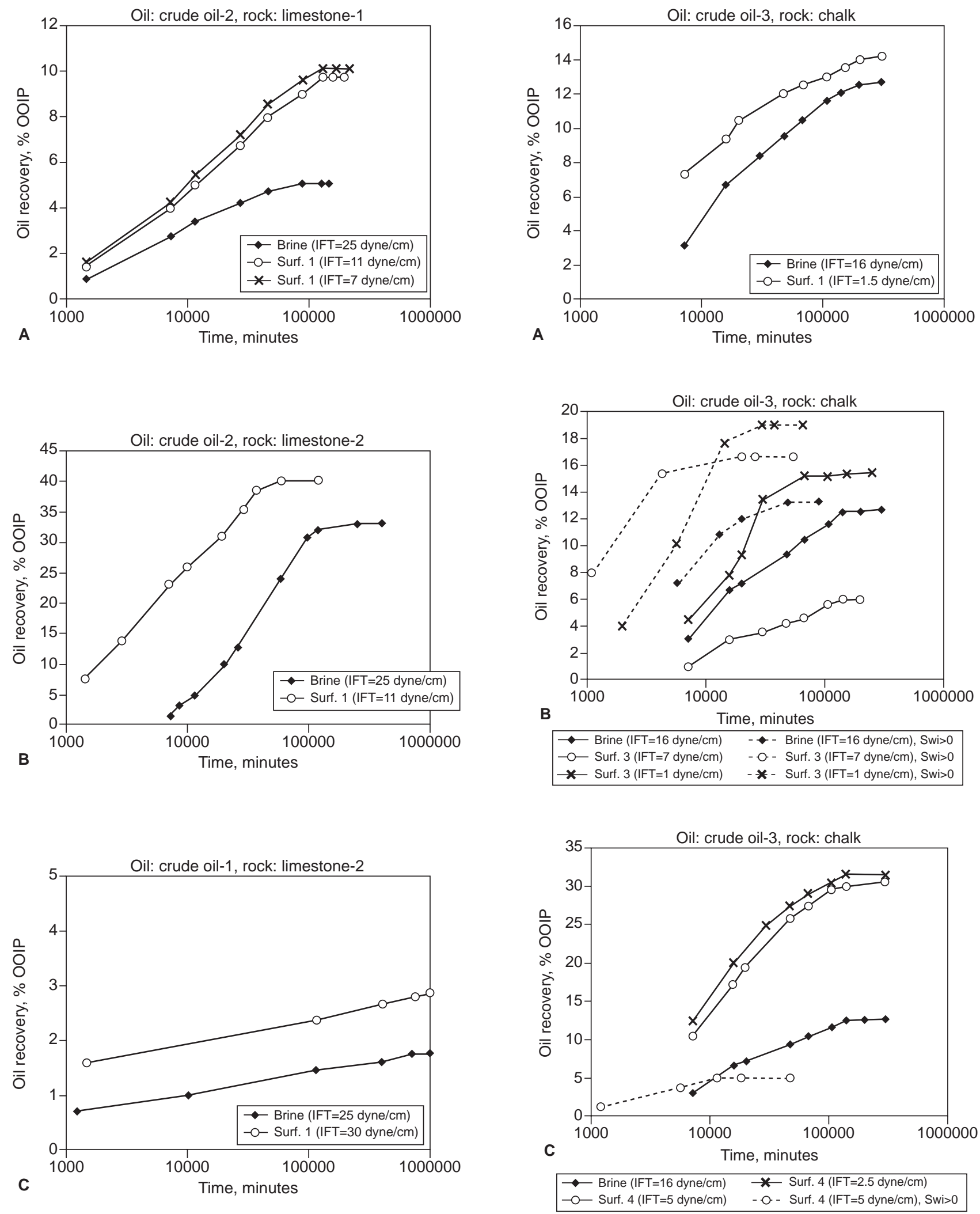

Figure 3

Spontaneous imbibition from cylindrical limestone samples for different oleic/aqueous phase pairs.

Figure 4

Spontaneous imbibition from cylindrical chalk samples for different oleic/aqueous phase pairs. 
Note that the surfactant concentration yielding IFT $=1$ is close to the CMC value (slightly above the CMC).

For the non-ionic surfactant (Fig. 4c), the ultimate recovery was much higher than that of the brine. On the other hand, the recovery rate was faster when there was no initial water in the system. For IFT $=5$ dyne/cm the experiment was repeated with initial water and the recovery was lower than that of brine (Fig. 4c). Note that for both cases, the surfactant concentration values are below the CMC.

We observe two different behaviors with two different surfactant types. Different recovery rates and ultimate recoveries were obtained for different surfactant types (Surf. 3 and 4). Surf. 4 yielded higher ultimate recovery even with lower IFT (5 dyne/cm) than Surf. 3 (1 dyne/cm). It is expected that both wettability alteration with the addition of surfactant and adsorption play a role in this different behavior. Note also that the IFT value of 1 dyne/cm for Surf. 3 is close to CMC, as mentioned above. This might affect the type and properties the emulsion that eventually play a role on the recovery rate.

As a final point, a few more comments need to be made in regards to the behavior of surfactant solution imbibition. Surf. 3 is an emulsion breaker whereas Surf. 4 is commonly used to create a stable microemulsion. The solubility of the surfactant in oil and water (hydrophilic and hydrophobic groups) and the type of emulsion, if exists, need to be taken into account. Recently, Babadagli and Boluk [23] reported that the solubility of surfactant solutions characterized by the organic and inorganic values of them (or HLB number) is related to the ultimate oil recovery by the capillary imbibition of surfactant solutions. They correlated the ultimate oil recovery to the organic and inorganic values of the surfactants used in the experiments for the cases with and without initial water.

\subsection{Quantitative Analysis}

Oil recovery from a reservoir matrix in naturally fractured reservoirs is characterized by two parameters:

- ultimate recovery (or residual oil);

- recovery rate.

For the quantitative analysis of the results, the evaluations will be made for these two parameters.

\subsubsection{Ultimate Recovery}

Both gravity and capillarity effects should be considered to identify the dynamics of the capillary imbibition for low IFT or long matrices. First analysis was performed for the ultimate recovery change with the inverse Bond number. The Bond Number is defined as the ratio of gravity forces to the capillary forces $(E q .1)[4,24,25]$ and usually expressed as the inverse of this $\left(N_{B}^{-1}\right)$ :

$$
N_{B}^{-1}=c \frac{\sigma f(\theta) \sqrt{\frac{\phi}{k}}}{\Delta \rho g H}
$$

where $\mathrm{c}=0.4$ for capillary tube models and this constant was used for all cases. In this analysis the wettability effect, represented by $f(\theta)$, was not considered. In Equation (2), all the units are in metric system, i.e., $k$ is $\mathrm{cm}^{2}, \sigma$ is dyne/cm, $H$ is $\mathrm{cm}$, and $\rho$ is $\mathrm{g} / \mathrm{cc}$.

The ultimate recoveries were plotted against $N_{B}^{-1}$ in Figure 5. Previously, similar plots were done for the same sandstones with different permeabilities [6] and one kind of sandstone and limestone [4] without also considering the wettability effect. Here, wide ranges of rock, oil and surfactant types were included. Typically, the ultimate recovery decreases with increasing $N_{B}^{-1}$. Two trends, however, were observed. Sandstone and limestone sample-2 (LS-2) followed the same trend, whereas the chalk samples and other limestone (LS-1) followed another trend. The both trends showed an exponential behavior. Note that the wettability characteristics are not included and these two groups of rocks in each trend are expected to represent a similar wettability characteristics based on the ultimate recovery measures. Note that the quantification of the intrinsic wettability for surfactant solutions using imbibition data is rather difficult. The change in the imbibition rate is an identification of the wettability but it is also influenced by the change in the IFT. Therefore, the wettability effect was not included. With the inclusion of the wettability term $[f(\theta)]$ however, the two groups of curves are expected to follow a single trend as suggested and shown by Babadagli $[5,15]$.

\subsubsection{Recovery Rate}

The shape of the recovery curve is an indication of the interaction type and the contribution of the capillary and gravity forces. In strongly water-wet systems with light oil, the matrix-fracture interaction is expected to be countercurrent for short rock samples. In order for the gravity to become effective in the transfer, the sample size (height) should be big enough or the capillary forces should be weak. In this case, the interaction becomes fully or partly cocurrent. For example, the shapes of the curves in Figure 1d are different from the ones in Figures 2a and b, indicating that the transfer between matrix and fracture is not predominantly capillary imbibition and not fully countercurrent.

The recovery rates can also be compared using the dimensionless groups after normalizing them. The normalization is done by dividing the amount recovered by the ultimate recovery. The dimensionless groups can also be used to identify the recovery mechanism and interaction type implicitly. 


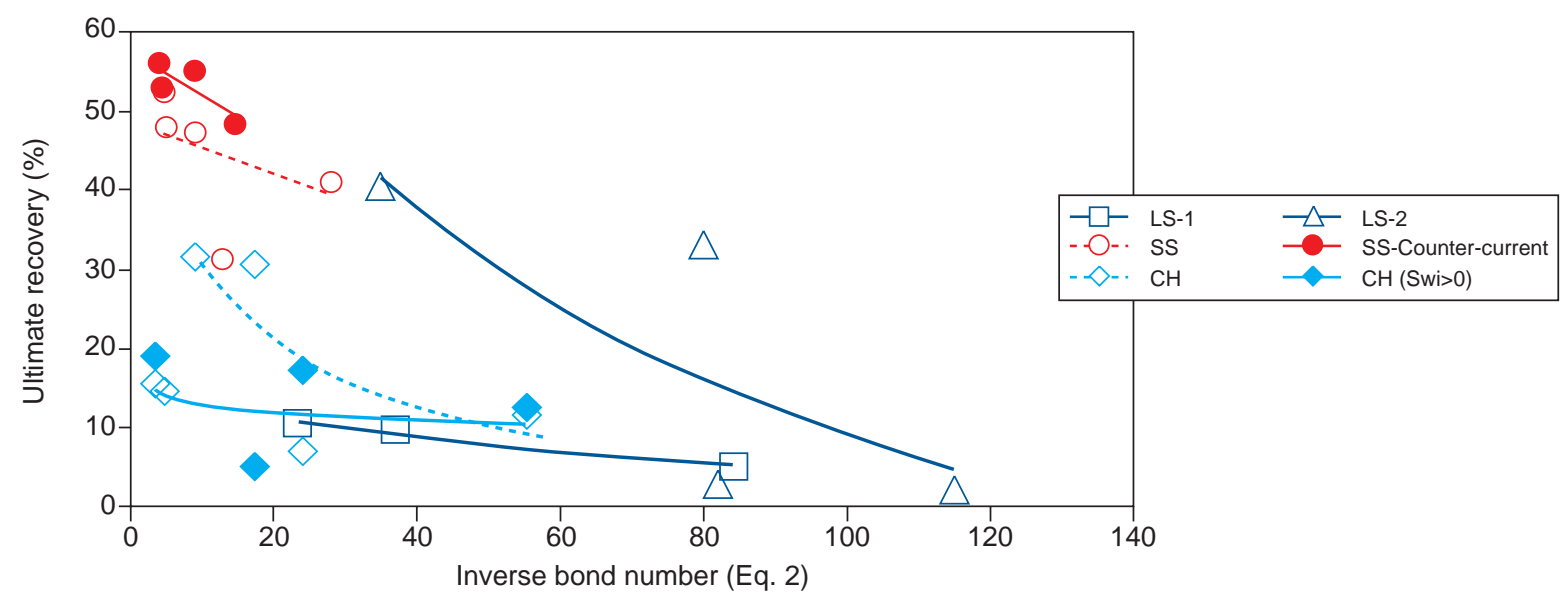

Figure 5

The change of the imbibition ultimate recoveries with the Inverse Bond Number for different rock, oil, and surfactant samples.
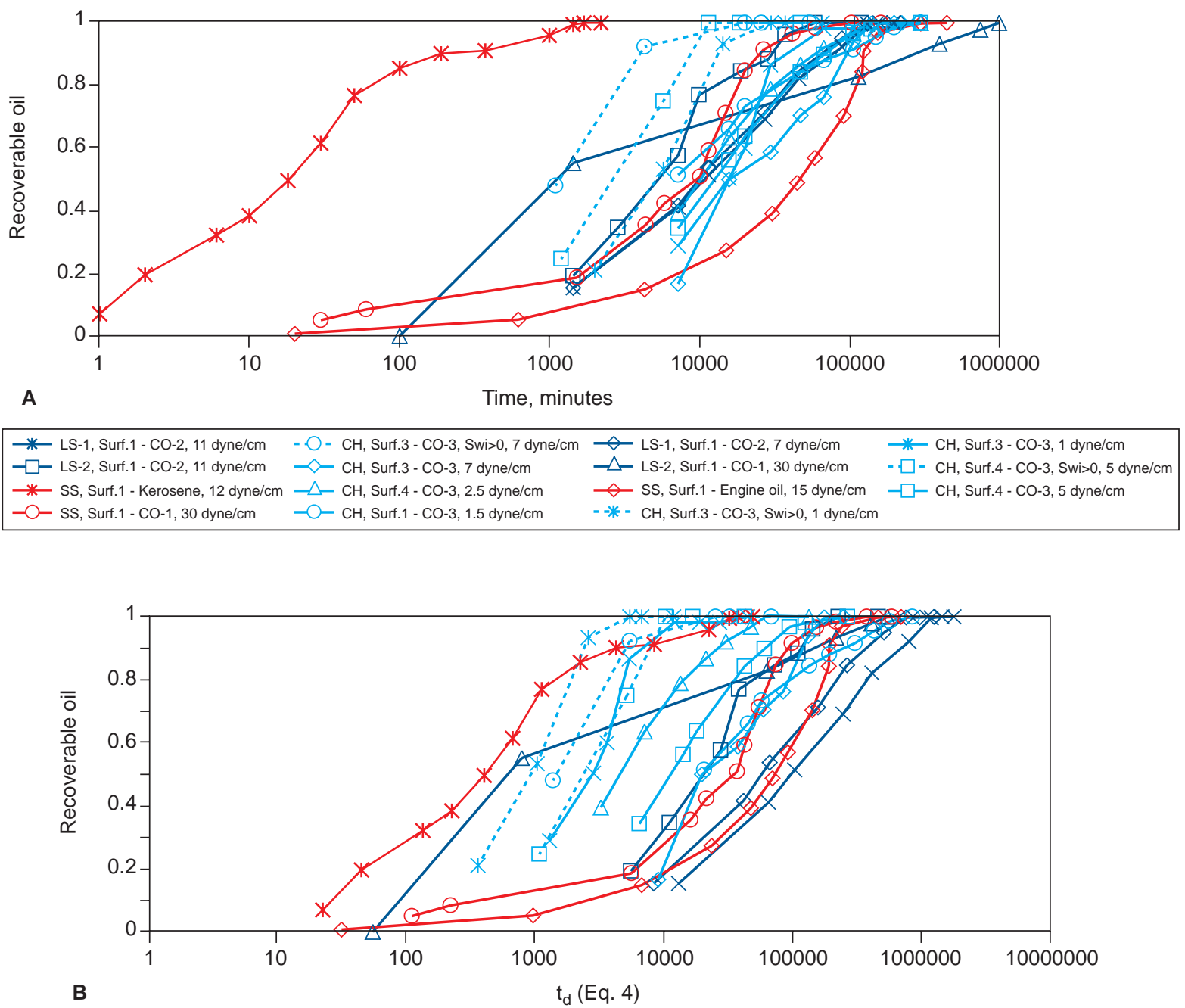

Figure 6

Recoverable oil against the recovery time and the dimensionless imbibition scaling group (Eq. 5) for different rock, oil, and surfactant samples. 
Cuiec et al. [3] proposed a modification to the classical Mattax and Kyte [21] dimensionless scaling group (Eq. 1) replacing water viscosity by oil viscosity. Zhang et al. [26] combined the oil and water viscosities as the geometric mean of the viscosity $\left(\mu_{g m}=\sqrt{\mu_{o} \mu_{w}}\right)$ to replace $\mu_{w}$ in Equation (1).

If $L$ in Equation (1) is replaced by the characteristics length, $L_{c}$, as described below [27] based on the boundary condition of the matrix:

$$
L_{c}=\frac{1}{\sqrt{F_{s}}}=\sqrt{\frac{V_{b}}{\sum_{i=1}^{n} \frac{A_{i}}{l_{A i}}}}
$$

then Equation (1) can be rewritten as follows:

$$
t_{d}=t \frac{\sigma}{\mu_{g m} L_{c}^{2}} \sqrt{\frac{k}{\phi}}
$$

When the field units are used as given in the Notations, Equation (4) should be multiplied by a conversion constant of 0.0188. Characteristic lengths were calculated using Equation (3). For the cylindrical samples open to flow from all directions, the $\mathrm{L}_{\mathrm{c}}$ 's are $0.68,0.87$ and $0.88 \mathrm{~cm}$ for the samples sizes of $5,7.5$, and $10 \mathrm{~cm}$ in length and 2.54 in diameter, respectively. For the samples with $10 \mathrm{~cm}$ in length and $3.81 \mathrm{~cm}$ in diameter, it is $1.3 \mathrm{~cm}$.

Figure 6 shows the recoverable oil against time (Fig. 6a) and the dimensionless time given in Equation (4) (Fig. 6b). If the matrix-fracture transfer is dominated by capillary imbibition, it is expected that the curves show the same behavior when plotted against the dimensionless group. All the chalk cases without initial water (solid light blue curves) followed the same trend against the time. They did not show a similar trend when plotted against the dimensionless group. This indicates that the transfer is not predominantly capillary imbibition. The curves for sandstone and limestone samples showed two groupings. One group contains the all curves for sandstone and limestones except the SS/kerosene and LS$1 / \mathrm{CO}-1$ cases (the right side of the curve bundles). Other group contains sandstone with kerosene, LS-2 and the chalk cases with initial water (the left side of the curve bundles). The curves on the right side are the weak capillary imbibition cases whereas the ones on the left side of the bundle are stronger capillary imbibition cases. The shape of the curves also implies this. Schechter et al. [4] suggested that the shape of the curves becomes concave as the effect of capillarity decreases. Let us take the two extreme examples of the curves. Sandstone with kerosene represents the fastest recovery rate and it is capillary dominated imbibition transfer. The recovery is expected to be due totally to counter-current imbibition. Engine oil case, however, is not fully dominated by capillarity due to higher viscosity and weaker water wettability characteristics. The recovery is slower and not fully counter-current imbibition as implied by the concave shape.

Once the wettability effect is taken into account, the two groups of curves might show a grouping. The inclusion of wettability in the formulation is a crucial issue but the effect of surfactant on the wettability should be identified first. Contact angle $(\theta)$ is a measure of the wettability and the numerator of Equations (1) and (4) is multiplied by $\cos (\theta)$ in order to incorporate the wettability effect. But the quantification of the wettability through this measurement is difficult task. Thus, another practical measure of wettability should replace the $\cos (\theta)$. Babadagli $[5,15]$ suggested a relative measure of wettability based on capillary imbibition method and suggested to use a value between 1 and 0 to represent wettability.

If the gravity dominates the interaction between matrix and fracture, i.e., IFT is lowered or much longer cores are used, the gravity becomes also effective on the recovery. A scaling group for gravity dominated capillary imbibition was defined by Du Prey [24] as follows:

$$
t_{g}=t \frac{k \Delta \rho}{L \phi \mu_{w}}
$$

Cuiec et al. [3] proposed a modification to this equation and used $\mu_{o}$ instead of $\mu_{w}$. This is more suitable for our case as different oil types were used. Equation (5) can be written in the following form to define the dimensionless time for the imbibition process dominated by the gravity forces:

$$
t_{g}=t \frac{k \Delta \rho}{L \phi \mu_{o}}
$$

The recoverable oil was plotted against these two dimensionless groups in Figure 7. If the gravity fully dominates the interaction, the same trend is expected for all the curves. In both cases, there is no such trend when they are compared to the curves given in Figure 6a. Due to the small size of the cores and a certain degree of water wettability, one can expect no significant effect of gravity in the recovery. But as mentioned earlier, the interaction type can be co-current driven from the bottom of the core towards the upper part and the counter-current imbibition can be observed only on the top portion of the core once the capillary forces become weaker. This is a possibility in the cases of heavy-crude oil, limestone and chalk samples without an initial water, and engine oil with sandstone. Therefore, other dimensionless scaling groups suggested by Schechter et al. [4] were tested to identify the interaction type.

They defined the following dimensionless groups as similar to the Equations (1), (3), (4) and (5). Characteristic time, tc is defined for capillary dominated matrix transfer: 

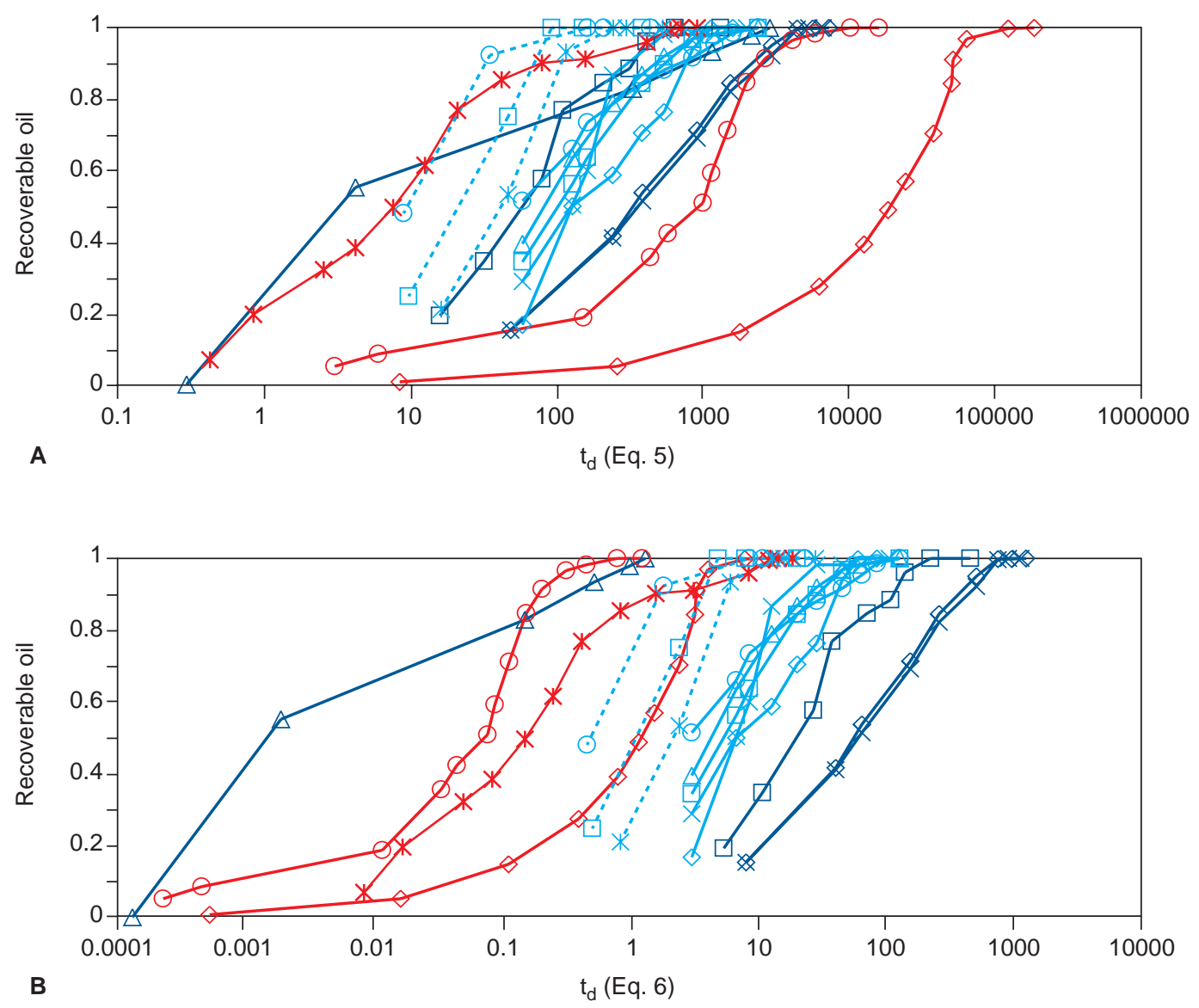

Figure 7

Recoverable oil against the dimensionless gravity scaling groups (Eqs. 7 and 8) for different rock, oil, and surfactant samples. Legend given in Figure 6.

$$
t_{c_{1}}=t \frac{R^{2} \phi}{\operatorname{C\sigma \lambda } \sqrt{\frac{k}{\phi}}}
$$

Characteristic time, $t_{c}$ is defined for gravity driven flow matrix transfer:

$$
t_{c_{2}}=t \frac{H^{2} \phi}{\operatorname{C} \sigma \lambda} \sqrt{\frac{k}{\phi}}
$$

In fact, if the capillary imbibition takes place in countercurrent manner in vertically situated cylindrical cores, it is controlled by the diameter of the core $(R, E q .7)$. If the transfer is not counter-current, the oil is displaced from bottom towards the upper part of the core in co-current manner. Counter-current imbibition may take place in the upper parts of the core depending on the strength of the capillary forces. In this case, the transfer is controlled by the height of the core $(H, E q .8)$.

Figure 8 shows the plots of recoverable oil against these two dimensionless groups. The differences among the cases representing different characteristics are more distinct compared to Figure $6 \mathrm{~b}$. There are mainly three groups of curves. In Figure 8a, the sandstone case with kerosene was separated due to it is very fast recovery rate by strong capillary imbibition. The second group of the curves (bundle of curves in the middle) consists of all limestones except the heavy oil case (CO-1) and the chalk cases with initial water except Surf. 3 and CO-3. The third group of the curves (the right most one) also represents a good grouping except the engine oil case. Note that in Figure $8 \mathrm{~b}$ the engine and heavy oil sandstone cases, which are not expected to have countercurrent type interaction even though they have capillary imbibition recovery, grouped along with the low IFT chalk case (Surf. 3-CO-3). These three cases are expected to be the weakest capillary dominated cases.

These plots are helpful in identifying the transfer type. Towards the right direction in these plots, the transfer type becomes less counter-current dominated (as shown in the schematic between the plots). The two cases of sandstone with engine and heavy oil are good examples of this type of flow. In this case, the shape of the curves becomes more concave as an indication of co-current interaction. These 

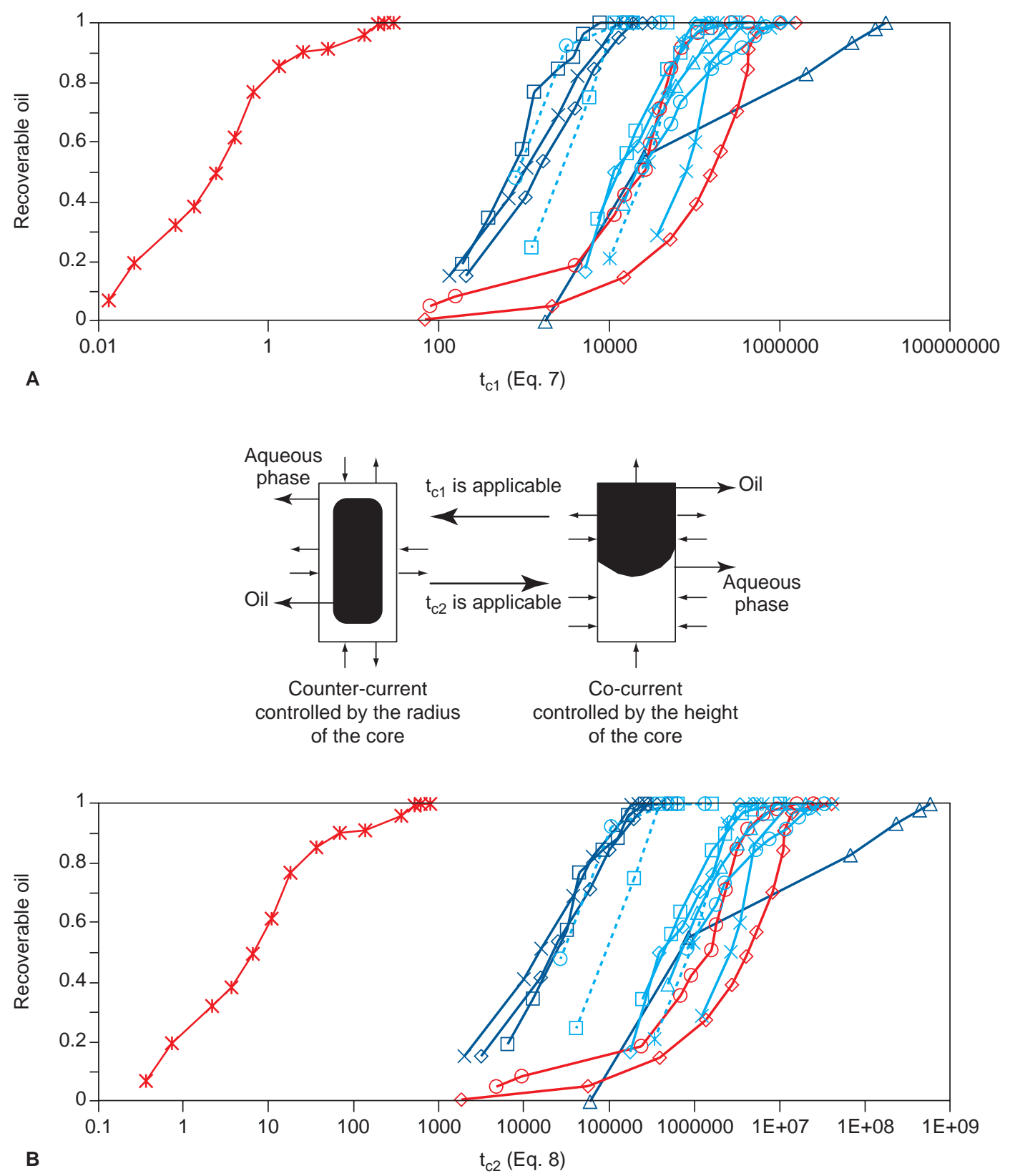

Figure 8

Recoverable oil against two dimensionless imbibition scaling groups (Eqs. 9 and 10) for different rock, oil, and surfactant samples. Legend given in Figure 6. The schematic between the graphs shows the expected interaction types.

observations verify Schechter et al.'s [4] and Austad and Miller's [7] findings. The sandstone with kerosene case is far away from all the other curves. The sandstone case with kerosene is a good example of counter current flow and in both plots it did not belong to any other groups. This indicates that the other curves do not represent a fully counter-current interaction.

The way the curves were grouped is similar in Figures 8a and $b$. This indicates that the interactions are not fully counter-current nor co-current, except the sandstone/kerosene case, which is fully counter-current imbibition. In some particular cases, a better grouping of the curves can be observed. For example, two sandstone cases with Surf. 1/ CO-1 and Surf.1/engine oil are closer to each other in Figure $8 \mathrm{~b}$. This is an implication of the stronger contribution of co-current interaction than counter-current and Equation (8) is more convenient than Equation (7) for the scaling of these types of cases. 
Zhou et al. [28] suggested an improved version of Equation (4) using the mobility $\left(\lambda=k_{i} / m_{i}\right)$ as in the Equations (7) and (8). This approach was not tested in this study due to difficulties in determining the mobility values.

As a final attempt, another approach was tested. RangelGerman and Kovscek [29] recently suggested that the recovery scale with time for 2-D plane with line source, the square root of time for 1-D geometry, and with $t^{3 / 2}$ for 3-D geometry. Both $t$ and $t^{3 / 2}$ plots did not exhibit a straight line behavior. In all cases except LS, a straight line was obtained when the recovery rate (as cc) was plotted against $t^{1 / 2}$. Straight line relationship between the imbibition rate $(q)$ and $t^{1 / 2}$ indicates that the imbibition progresses in linear manner from a plane source $[29,30]$. In our experiments, the interaction between matrix and surrounding fluid is planar rather than a point. Also note that the imbibition progresses in linear manner and this could be the case for both strongly capillary dominated (counter-current flow) and slightly capillary dominated cases (co-current flow with some counter-current from the top portion of the core) indicated by low and high $N_{B}^{-1}$ values, respectively.

\section{CONCLUSIONS AND REMARKS}

The conditions yielding increased recovery rate and ultimate recoveries by the capillary imbibition of surfactant solution were identified. Non-ionic surfactant solution increased the recovery rate and ultimate recovery of heavy-oil in water-wet sandstone compared to the brine imbibition (high IFT). No such effect was observed for the recovery rate of the countercurrent imbibition (imbibition taking place only from one side of the core) for lighter crude oil even though a slight increase in the ultimate recovery was obtained by surfactant addition. Except light oil cases such as kerosene and light crude oil in sandstones, in all cases (limestone, sandstone with heavy-crude and chalk samples) the same surfactant solution (a non-ionic surfactant) yielded a higher ultimate recovery and faster recovery rate. This can be attributed to the change in wettability by addition of this non-ionic surfactant.

When an anionic surfactant was used in chalks, low IFT (higher surfactant concentration) yielded higher recovery than the brine case. Lower surfactant concentration, however, resulted in lower recovery than the brine case. A non-ionic surfactant, on the other hand, showed very effective recovery regardless the concentration of surfactant.

Having initial water in the system (irreducible water saturation) resulted in faster recovery of light crude oil in chalks compared to the samples without initial water for anionic surfactant. The opposite was observed for non-ionic surfactant. Despite its very effective recovery for the samples without initial water, the recovery rate and the ultimate recovery from the chalk sample with initial water was lower than those of brine.

A correlation between the ultimate recovery and the Inverse Bond Number was obtained. As the Inverse Bond Number (Eq. 2) increases the ultimate recovery decreases.

The shape of the recovery curves was found to be a good indicator for the strength of the capillary forces in the imbibition transfer. The dimensionless scaling groups were tested for the applicability of them for scaling and to identify the mechanics of capillary imbibition. A modified version of the classical Mattax and Kyte group was tested without considering the wettability effect. No scaling behavior was observed. Obviously, the interactions were not fully capillary dominated and not in a counter-current manner. The dimensionless group for the gravity-dominated imbibition did not show any scaling behavior for any cases either. Two dimensionless groups suggested by Schechter et al. [4] were tested as an alternative to Mattax and Kyte type dimensionless group. A better scaling, suggesting the inclusion of the wettability factor, was observed and it was shown that these groups could be used to also distinguish the interaction type, i.e., the strength of the capillarity on the imbibition transfer.

The experimental work showed that the surfactant solutions could be used in the fractured reservoirs for enhanced oil recovery. Significant reduction in the residual oil saturation was obtained when surfactant solutions were used instead of brine. This is more prominent for less waterwet rocks like limestone and chalks, which are potential -naturally fractured - reservoir types in Europe (North Sea), the Middle East (fractured limestones) and North America (West Texas and Mexico). The selection of proper surfactant type and concentration is critical depending on the amount of initial water, rock, and oil type. Performance estimation of the field applications through scaling formulations should be done carefully. Attention should be given to the dominant displacement mechanism (capillarity or gravity) that is controlled by the matrix size and wettability.

\section{ACKNOWLEDGEMENTS}

This study was partly funded by an NSERC Grant (No: G121210595). This paper is the revised version of SPE 84866 presented at the 2003 SPE Asia Pac. Imp. Oil Rec. Conf., Kuala Lumpur, Malaysia, Oct. 20-21, 2003.

\section{REFERENCES}

1 Keijzer, P.P.M. and de Vries, A.S. (1990) Imbibition of Surfactant Solutions. SPE 20222 presented at the 1990 SPE/DOE 7th Symp. on Enhanced Oil Recovery, Tulsa, OK, April, 22-25.

2 Flumerfelt, R.W. et al. (1993) A Cyclic Surfactant-Based Imbibition/Solution Gas Drive Process for Low-Permeability, 
Fractured Reservoirs. Paper SPE 26373 presented at the 1993 SPE Ann. Tech. Conf. and Exh., Houston, TX, Oct., 3-6.

3 Cuiec, L., Bourbiaux, B. and Kalaydjian, F. (1994) Oil Recovery by Imbibition in Low-Permeability Chalk. SPEFE (Sept.) 200.

4 Schechter, D.S., Zhou, D. and Orr, F.M. (1994) Low IFT Drainage and Imbibition. J. Pet. Sci. and Eng., 11, 283.

5 Babadagli, T. (1996) Temperature Effect on Heavy-Oil Recovery Imbibition in Fractured Reservoirs. J. Pet. Sci. and Tech., 14, 197.

6 Al-Lawati, S. and Saleh, S. (1996) Oil Recovery in Fractured Oil Reservoirs by Low IFT Imbibition Process. Paper SPE 36688 presented at the 1996 SPE Annual Tech. Conf. and Exh., Denver, CO, Oct. 6-9.

7 Austad, T. and Milter, J. (1997) Spontaneous Imbibition of Water Into Low Permeable Chalk at Different Wettabilities Using Surfactants. Paper SPE 37236 presented at the 1997 SPE Int. Symp. On Oilfield Chemistry, Houston, TX, Feb. 1821.

8 Milter, J. and Austad, T. (1996) Chemical Flooding of Oil Reservoirs 6. Evaluation of the Mechanism for Oil Expulsion by Spontaneous Imbibition of Brine With and Without Surfactant in Water-Wet, Low-Permeable, Chalk Material. Coll. and Surf. A: Phys. and Eng. Aspects, 113, 269.

9 Austad, T. et al. (1998) Chemical Flooding of Oil Reservoirs 8. Spontaneous Oil Expulsion From Oil- and Water-Wet Low-Permeable Chalk Material by Imbibition of Aqueous Surfactant Solutions. Coll. and Surf. A: Phys. and Eng. Aspects, 137, 117.

10 Babadagli, T. (2001) Improving Matrix-Fracture Transfer Using Chemicals and Thermal Methods in Fractured HeavyOil Reservoirs, CIPC 2001-130, 52nd Annual Tech. Meet., Canadian Int. Petr. Conf., June 12-14, Calgary, Alberta, Canada.

11 Spinler, E.A. (2000) Enhancement of Oil Recovery Using a Low Concentration of Surfactant to Improve Spontaneous and Forced Imbibition in Chalk. Paper SPE 59290 presented at the 2000 SPE/DOE Imp. Oil. Rec. Symp., Tulsa, OK, April, 3-5.

12 Chen, H.L. et al. (2000) Laboratory Monitoring of Surfactant Imbibition Using Computerized Tomography. Paper SPE 59006 presented at the 2000 SPE Int. Petr. Conf. and Exh., Veracruz, Mexico, Feb., 1-3.

13 Babadagli, T. (2003) Selection of Proper Enhanced Oil Recovery Fluid for Efficient Matrix Recovery in Fractured Oil Reservoirs. Coll. and Surf. A: Physic. and Eng. Aspects, 223, 157-175.
14 Babadagli, T. (2003) Evaluation of EOR Methods for HeavyOil Recovery in Naturally Fractured Reservoirs. J. of Petroleum Science and Eng., 37, 25.

15 Babadagli, T. (2001) Scaling of Co-Current and CounterCurrent Capillary Imbibition for Surfactant and Polymer Injection in Naturally Fractured Reservoirs. SPEJ (Dec.), 6, 465 .

16 Alveskog, P. L., Holt, T. and Torsaeter, O. (1998) The Effect of Surfactant Concentration on the Amott Wettability Index and Residual Oil Saturation. J. of Petr. Sci. and Eng., 20, 247.

17 Standnes, D.C., and Austad, T. (2000) Wettability Alteration in Chalk 2. Mechanism for Wettability Alteration from OilWet to Water-Wet Using Surfactants. J. of Petr. Sci. and Eng., 28, 123.

18 Baldwin, B.A. and Spinler, E.A. (2002) In Situ Saturation Development During Spontaneous Imbibition. J. of Petroleum Sci. and Eng., 35, 23.

19 Weisbord, N., Niemet, M.R. and Selker, J.S. (2002) Imbibition of Saline Solutions into Dry and Prewetted Porous Media. Adv. in Water Res., 25, 841.

$20 \mathrm{Li}, \mathrm{K}$., Chow, K. and Horne, R. (2002) Effect of Initial Water Saturation on Spontaneous Water Imbibition. Paper SPE 76727 presented at the 2002 SPE Western Reg. Meet., Anchorage, Alaska, May, 20-22.

21 Mattax, C.C. and Kyte, J.R. (1962) Imbibition Oil Recovery from Fractured Water Drive Reservoirs. Trans. AIME, 225, 177.

22 Babadagli, T. (2002) Dynamics of Capillary Imbibition When Surfactant, Polymer and Hot Water Are Used as Aqueous Phase. J. Coll. and Int. Sci., 246, 203-213.

23 Babadagli, T. and Boluk, Y. (2005) Oil Recovery Performances of Surfactant Solutions by Capillary Imbibition. J. Coll. and Int. Sci., 282, 158-171.

24 Lefebvre Du Prey, E. (1978) Gravity and Capillarity Effects on Imbibition in Porous Media. SPEJ (June), 195.

25 Iffly, R., Rousselet, D.C. and Vermeulen, J.L. (1972) Fundamental Study of Imbibition in Fissured Oil Fields, SPE 4102 presented at the 1972 SPE Annual Fall Meet, San Antonio, TX, Oct. 8-11.

26 Zhang, X., Morrow, N. and Ma, S. (1996) Experimental Verification of a Modified Scaling Group for Spontaneous Imbibition. SPERE (Nov.), 273.

27 Ma, S., Morrow, N.R. and Zhang, X. (1997) Generalized Scaling of Spontaneous Imbibition Data For Strongly WaterWet Systems. J. Pet. Sci. and Tech., 18, 165. or distributed for profit or commercial advantage and that copies bear this notice and the full citation on the first page. Copyrights for components of this work owned by others than IFP must be honored. Abstracting with credit is permitted. To copy otherwise, to republish, to post on servers, or to redistribute to lists, requires prior specific permission and/or a fee: Request permission from Documentation, Institut français du pétrole, fax. +33147527078 , or revueogst@ifp.fr. 